\title{
Does the $A C E$ I/D polymorphism, alone or in combination with the ACTN3 R577X polymorphism, influence muscle power phenotypes in young, non-athletic adults?
}

\author{
Gabriel Rodríguez-Romo - Jonatan R. Ruiz • Catalina Santiago • \\ Carmen Fiuza-Luces · Marta González-Freire · Félix Gómez-Gallego • \\ María Morán · Alejandro Lucia
}

\begin{abstract}
We investigated the association of the angiotensin converting enzyme gene $(A C E)$ insertion/deletion (I/D) polymorphism, alone or in combination with the $\alpha$-actinin-3 gene (ACTN3) R577X polymorphism. with jumping (vertical squat and counter-movement jump tests) and sprint ability $(30 \mathrm{~m}$ dash) in non-athletic. healthy young adults $[N=281$ ( 214 male), mean (SD) age 21 (2) years]. We did not observe any effect of the ACE I/D polymorphism on study phenotypes. We repeated the analyses separately in men and women and the results did not materially change. Likewise, the mean estimates of the study phenotypes were similar in subjects with the genotype combinations $A C E \mathrm{II}+\mathrm{ID}$ and $A C T N 3 \mathrm{XX}$ or $A C E$ $\mathrm{DD}$ and $A C T N 3 \mathrm{RR}+\mathrm{RX}$. We found no association between the $A C E \mathrm{DD}$ and $A C T N 3 \mathrm{RR}+\mathrm{RX}$ genotype combination and performance ( $\geq 90$ th of the sex-specific
\end{abstract}

G. Rodríguez-Romo

INEF, Universidad Politécnica de Madrid, Madrid, Spain

J. R. Ruiz

Department of Biosciences and Nutrition at NOVUM,

Unit for Preventive Nutrition, Karolinska Institutet.

Stockholın, Sweden

C. Santiago - C. Fiuza-Luces - M. González-Freire

F. Gómez-Gallego - A. Lucia

Universidad Europea de Madrid,

Villaviciosa de Odón, 28670 Madrid, Spain

e-mail: alejandro.lucia@uem.es

M. Morán

Centro de Investigación Hopsical 12 de Octubre and CIBERER,

Madrid, Spain percentile). In summary, though the $A C E$ I/D polymorphism is a strong candidate to modulate some exerciserelated phenotypes or athletic performance status. this polymorphism. alone or in combination with the ACTN3 R577X polymorphism, does not seem to exert a major influence in the muscle 'explosive' power of young healthy adults, as assessed during multi-joint exercise tests.

Keywords Jump - Sprint - Genes .

Genotype;phenotype association

\section{Introduction}

One genetic variation that is a candidate to explain individual variability in exercise-related phenotypes. and parricularly in muscle phenotypes is the $287 \mathrm{bp}$ insertion/ deletion (I/D) polymorphism of the angiotensin converting enzyme ( $A C E$ ) gene. Besides regulating blood pressure, the ACE is expressed in skeletal muscle, where it may influence its function and biomechanical properties (Gordon et al. 2001; Jones et al. 2002: Wagner et al. 2006), e.g. its product, angiocensin II. acts as a muscle growth factor (Jones et al. 2002) that is necessary to induce overloadinduced skeletal muscle hypertrophy (Gordon et al. 2001). The ACE D allele is associated with higher ACE activity and thus increased angiotensin ll levels (Jones et al. 2002): thus, this allele would theoretically favour performance in power or strength-oriented versus more endurance exercise tasks. Indeed. the D allele has been associated with elite "sprint" athletic performance (Myerson et al. 1999: Woods et al. 2001) and power-related phenotypes in non-athletic populations. e.g. preserved quadriceps muscle strength in chronic patients (Hopkinson et al. 2004), lower risk of skeletal muscle damage induced by eccentric contractions 
(Yamin et al. 2007), or greater gains in knee extensor strength after training in old ( $\geq 60$ years) individuals (Giaccaglia et al. 2008).

Another strong candidate to influence muscle phenotypes is the $A C T N 3$ gene, which encodes for the synchesis of $\alpha$-actinin-3 in skeletal-muscle fibres, a protein necessary for producing fast, powerful contractions (Yang et al. 2003). A premature stop codon polymorphism (R577X) in ACTN3 was first described by North et al. (1999). Though this genetic variation is not associated with any known disease phenotype, the $\alpha$-actinin-3-deficient XX genotype is believed to preclude top-level athletic performance in 'pure' power and sprint sports (e.g. sprinting and jumping events), especially in women (Yang et al. 2003). More discrepancy exists on the putative role of the $A C T N 3$ R577X polymorphism on muscle power phenotypes in non-athletic populations, with some auchors reporting an unfavourable effect of the XX genotype (Vincent et al. 2007), at least in women (Walsh et al. 2008), and orhers reporing no effect (McCauley et al. 2009). Additional controversy stems from the fact that in older adults (mean age $\sim 65$ years), the $\mathrm{XX}$ genotype was associated with higher knee extensor concentric peak power compared with RR and RX genotypes (Delmonico et al. 2007), while others found no genotype:phenotype association (San Juan et al. 2006). We recently reported no association between leg explosive muscle power (jump and sprint tests) and the ACTN3 R577X polymorphism in non-arhletic young adults (Santiago et al. 2009). It was concluded that muscle phenotype traits (e.g. power) are complex and thus not likely reducible to a single polymorphism such as $A C T N 3$ R577X. For instance, it could be that $A C E \mathrm{l} / \mathrm{D}$ and $A C T N 3$ $\mathrm{R} 577 \mathrm{X}$ polymorphisms act in combination to exert their influence in exercise-related phenotypes.

It was the main purpose of our study to examine the influence of the $A C E \mathrm{I} / \mathrm{D}$ polymorphism, alone or in combination with the $A C T N 3$ R577X polymorphisms, in the muscle power phenotypes of non-athletic adults. We hypothesized that, though the more 'endurance-orienced' $A C T N 3 \mathrm{XX}$ genotype is not associated with lower muscle explosive power (in jump and sprint tests) as we previously showed (Santiago et al. 2009), the combination of the $A C T N 3$ R577X and ACE ID polymorphisms may partly explain the individual variability in muscle strength phenotypes among young adults.

\section{Methods}

Subjects

Written consent was obtained from each subject. The study protocol was approved by the institutional ethics committee [Universidad Europea de Madrid (UEM), Spain] and was in accordance with the Declaration of Helsinki for Human Research. The study sample comprised 281 healthy young adults (University students) [mean (SD) age 21 (2) years (range 21, 32)] of boch genders (214 men, 67 women) who took part in a previous study on $A C T N 3$ R577X polymorphism (Santiago et al. 2009). Inclusion criteria were to be free of any diagnosed cardiorespiratory disease, and not to be engaged in competitive sports such as (a) formal, supervised 'power' (e.g. weight lifting or alpine skiing) or jumping oriented type of training (e.g. plyometrics, volleyball or basketball) or (b) endurance training (e.g. running, swimming of bicycling), i.e., performing less than one (power) or three (endurance) strictured weekly training sessions within the last year. All participants were of the same Spanish (Caucasian) ancestry for at least three generations.

\section{Genotype assessment}

Our study was designed and perfonmed in accordance with the recommendations for the human genotype-phenotype association studies recendy published by the NCI-NHGRI Working Group on Replication in Association Studies (Chanock et al. 2007). These recommendations include among others, the following items: indicating time period and location of subject recruitment, success rate for DNA acquisition. sample tracking methods or genotyping with a second technology in a second laboratory.

During winter-spring 2008, we extracted genomic DNA from saliva samples of the subjects in two different universities of the same city (Madrid. Spain): Universidad Politécnica and UEM ( $N=200$ and 84 subjects, respectively). Genotyping of the $A C T N 3$ R $577 \mathrm{X}$ polymorphism was performed during fall 2008 in the genetics laboratory of the UEM and the results have been previously published (Sanciago et al. 2009). The $A C E$ I/D genotyping was performed during spring 2010 in the same laboratory.

We followed the $A C E$ I/D (rs 1799752) and $A C T N 3$ R577X (Is1815739) genotyping methods that have been applied in previous studies (Gomez-Gallego et al. 2009; Santiago et al. 2009). Sequences comesponding to each polymorphism were amplified by the polymerase chain reaction (PCR) and the resulting PCR products were genotyped using electrophoresis through agarose gel $(A C E)$ or restriction fragment length polymorphisms (ACTN3). Primers used for the $A C E$ I/D polymorphism were: $5^{\prime}$-TG GAGACCACTCCCATCCTTTCT and 5 -GATGTGGCC ATCACATTCGTCAGAT. The PCR conditions were as follows: initial denaturing at $95^{\circ} \mathrm{C} 5 \mathrm{~min}$ : 35 cycles at $95^{\circ} \mathrm{C}$ $30 \mathrm{~s}, 58^{\circ} \mathrm{C} 30 \mathrm{~s}, 72^{\circ} \mathrm{C} 1 \mathrm{~min}$ and a final extension at $72^{\circ} \mathrm{C}$ $5 \mathrm{~min}$. The $A C E \mathrm{I} / \mathrm{D}$ fragments without insertion (D allele) and with insertion (I allele) of 190 and $490 \mathrm{bp}$, 
respectively, were detected on a $1.5 \%$ agarose gel containing ethidium bromide. In order to avoid a misclassification of ID heterozygotes as DD homozygotes, a second PCR reaction was performed in all of the samples initially classified as DD with the following insertion-specific primer pairs (Lindpaintner et al. 1995): 5'-TGGGACCACA GCGCCCGCCACTAC and 5'-TCGCCAGCCCTCCCAT GCCCATAA. The PCR conditions were similar as described above, except for the annealing temperature $\left(64^{\circ} \mathrm{C}\right)$. Only the allele I produces a $335 \mathrm{bp}$ amplicon, identified on an a $1.5 \%$ agarose gel stained with ethidium bromide. Figure 1 shows a representative example of visual detection of $A C E$ genotypes.

For the ACTN3 R577X polymorphism, a fragment of 291 bp was amplified with the following primers: ACTN3F $5^{\prime}$-CTGTTGCCTGTGGTAAGTGGG labelled a $5^{\prime}$ with
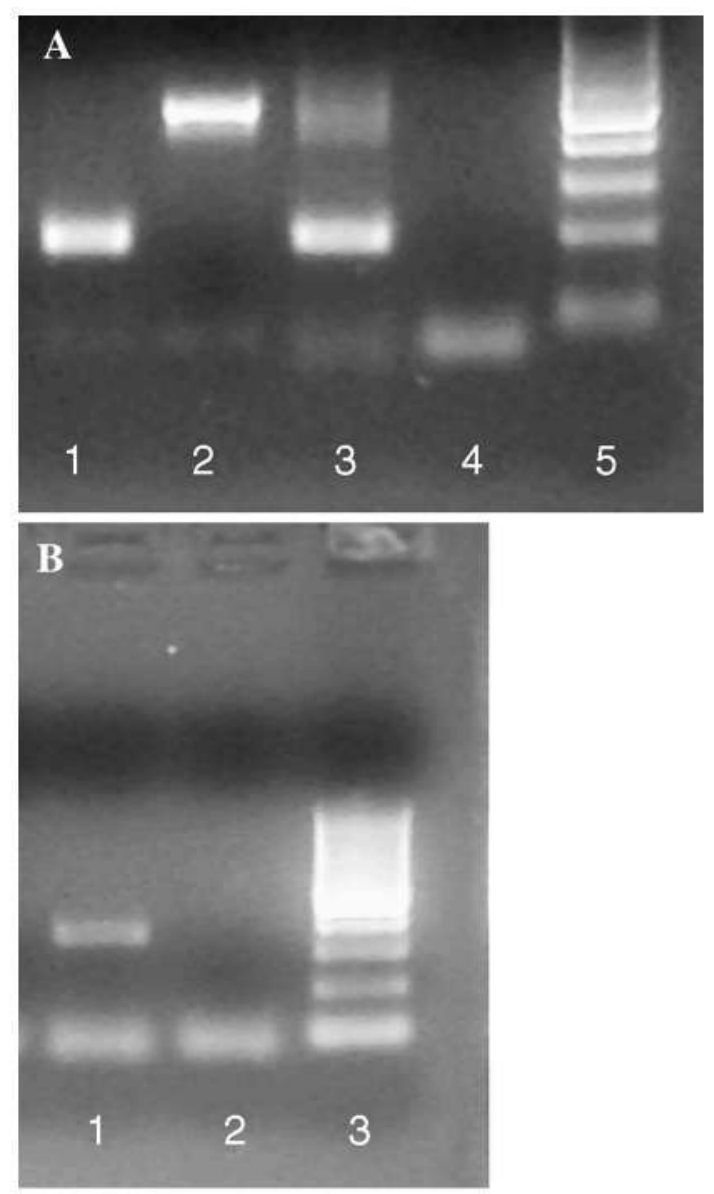

Fig. 1 Example of visual detection of $A C E$ genotypes. a (Upper figure) Representative gel of angiotensin converting enzyme gene (ACE) genotyping. Lane 1 Homozygous DD individual (190 bp), lane 2 homozygous II individual $(480 \mathrm{bp})$, lane 3 heterozygous ID individual (190 and $480 \mathrm{bp}$ ), lane 4 negative control, lane 5 Ladder $100 \mathrm{bp}$ (Biotools, Spain). b (Lower figure) Representative gel of internal $A C E$ genotyping. Lane 1 Positive internal ACE PCR (335 bp), lane 2 negative internal ACE PCing enzyme R, lane 3 Ladder 100 bp (Biotools, Spain)
VIC and ACTN3-R 5'-TGGTCACAGTATGCAGGAG GG. The PCR conditions were as follows: initial denaturing at $95^{\circ} \mathrm{C} 5 \mathrm{~min} ; 35$ cycles at $95^{\circ} \mathrm{C} 30 \mathrm{~s}, 60^{\circ} \mathrm{C} 30 \mathrm{~s}, 72^{\circ} \mathrm{C}$ $30 \mathrm{~s}$ and a final extension at $72^{\circ} \mathrm{C} 10 \mathrm{~min}$. ACTN 3 genotypes were established by enzymatic digestion of amplicons with Dde $I$. The R577X change creates a restriction site resulting in fragments of 108, 97 and 86 bp. Digestion of the R577 allele results in fragments of 205 and $86 \mathrm{bp}$, and digestion of the $577 \mathrm{X}$ allele results in fragments of 108, 97 and $86 \mathrm{bp}$. The digestion products detected by capillary electrophoresis (ABI Prism 310 genetic analyzer; Applied Biosystems, Foster City, CA) were those labelled with VIC, i.e. 108 bp for 577X, and 205 bp for R577.

Following recent recommendations (Chanock et al. 2007), genotype results of both $A C E$ I/D and ACTN3 R577X polymorphisms were replicated in 100 samples in a different laboratory (Progenika Biopharma, Parque Tecnológico de Zamudio, Derio-Vizcaya, Spain) using a different technology, i.e. newly developed low-density DNA microarray based on allele-specific probes. The design, fabrication, validation and analysis of the arrays were performed following the procedure described elsewhere (Tejedor et al. 2005). In brief, the PCR products were fluorescently labelled and hybridized to the DNA microarray in an automated platform (Ventana Medical Systems, Inc., Tucson, AZ, USA). The microarrays were scanned (Innopsys S.A., Carbonne, France) and we determined variants using a developed software that converts the intensity of the spots into the genotype of each variant.

No failures occurred in sample collection and DNA acquisition. Genotyping success rate was $>98.9 \%$ (three missing data for $A C E \mathrm{I} / \mathrm{D}$ and only one missing data for ACTN3 R577X). Parallel genotyping results of the two polymorphisms showed $100 \%$ concordance between the two laboratories (UEM and Progenika).

Phenotype assessment

Assessment of leg muscle 'explosive' power was performed during spring 2008 in the same location (UEM) and all the tests were supervised by the same researchers, as detailed elsewhere (Santiago et al. 2009). Squat (SJ) and counter-movement jump (CMJ) tests were performed using an infrared contact timing platform (Globus Ergo Tester, Codognè, Italy) to evaluate leg muscles' ability to produce 'explosive' power (Young et al. 2001). Both tests were performed three times (each separated by a 2-min rest period) and the best score was retained.

Subjects also performed a $30 \mathrm{~m}$ sprint test in an indoor rubberized track under two conditions: (1) starting from the stationary (standing) position (Young et al. 2001) and (2) starting with a previous $15 \mathrm{~m}$ run thereby allowing achieving higher speeds in the first meters of the test 
(Alcaraz et al. 2009). The difference in performance time between both tests (at 15 and $30 \mathrm{~m}$, respectively) was used as an index of subject's ability to produce acceleration, i.e. lesser difference implies higher acceleration capacity. We used photoelectric gaces at 0,15 and $30 \mathrm{~m}$ to start and stop a digital timer. We previously showed the reliability of the aforementioned tests for explosive leg muscle power assessment with a subgroup of the present subjects (Santiago et al. 2009).

\section{Statistical analysis}

Hardy-Weinberg equilibrium was tested using a $\chi^{2}$ test. we compared the genotype frequencies between males and females with the $\chi^{2}$ test.

We analysed the differences in the study phenotypes among variants of the $A C E \mathrm{I} / \mathrm{D}$ polymorphism by one-way analysis of covariance (ANCOVA), where the polymorphism was entered as a fixed factor, the phenotype was entered as a dependent variable, and age, weight and height were entered as covariates. We did not observe an interaccion effect of sex $\times A C E$ I/D polymorphism on the phenotypes (all $P>0.2$ ); therefore, all the analyses were performed with men and women together and sex was included as an additional covariate to the model.

We also analysed the combined effect of $A C E \mathrm{l} / \mathrm{D}$ and ACTN3 R577X polymorphisms on the study phenotypes by ANCOVA using two genotype combinations, i.e. $A C E \mathrm{DD}$ and ACTN3 RR + RX (which, at least hypochetically, might be more suitable for power/hypertrophy-oriented exercise tasks) versus $A C E \mathrm{II}+\mathrm{ID}$ and $A C T N 3 \mathrm{XX}$ group (Gomez-Gallego et al. 2009). We also compared the $A C E$ $\mathrm{DD}$ and $A C T N 3 \mathrm{RR}+\mathrm{RX}$ group against the rest of study participanss by ANCOVA.

Finally, in order to examine whecher the subjects with the best performance had also the 'best' genotype profile (i.e. $A C E$ DD and $A C T N 3 \mathrm{RR}+\mathrm{RX}$ ), we classified the population into two groups based on an arbitrary cut-off point: $\geq 90$ th of the sex-specific percentile and $<90 \mathrm{th}$ of the sex-specific percentile. The rationale for choosing 90th percentile was based on the fact that subjects in the top $10 \%$ might have a favourable genetic endowment to perform better. We performed logistic regression analysis to examine the association between the ACE DD and ACTN3 $\mathrm{RR}+\mathrm{RX}$ genotype combination and performance ( $\geq 90$ th of the sex-specific percentile) after adjusting for sex. age, weight and height. To further investigate the influence of the 90th percentile cut-off on the findings, we performed sensitivity analyses after varying these cut-offs ( $\geq 75 \mathrm{ch}$ and $\geq 95$ th).

All statistical analyses were performed using the PASW. We used the Bonferroni and Holm method to correct for multiple resting (Holm 1979; Shaffer 1995). This method proceeds as follows: Sort the $P$ values of the $k$ tests in increasing order, i.e., $P_{1}, P_{2}, \ldots, P_{i} \ldots, P_{k}$. If $P_{1}>\alpha / k$, none of the $k$ tests are significant, and the test procedure is finished. If $P_{1} \leq \alpha / k$, test 1 is significant, and now $P_{2}$ is examined. If $P_{2}>\alpha /(k-1)$, none of the $(k-1)$ remaining tests are significant, but if $P_{2} \leq \alpha /(k-1)$, test 2 is significant and $P_{3}$ is examined. This procedure goes on until $P_{i}>\alpha /(k-i+1)$.

\section{Results}

ACE I/D genotype distributions met Hardy-Weinberg equilibrium $\left(\chi^{2}=0.050, P=0.821\right)$. We did not observe differences $\left(\chi^{2}=2.225 . P=0.329\right)$ in the genotype distributions in men [30 (13.9\%), $103(47.7 \%)$ and $81(37.5 \%)$ for II, ID and DD, respectively] and women [9 (13.4\%), 26 $(38.8 \%)$ and $32(47.8 \%)$ for II. ID and DD, respectively]. The genotype distribution of the ACTN3 R577X polymorphism also respected the Hardy-Weinberg equilibrium and did not differ by sex (Santiago et al. 2009).

The association between the ACE I/D polymorphism and study phenotypes is presented in Table 1 . We did not observe any significant effect of the polymorphism on study phenotypes, alchough a 'minor trend' ( $P=0.063$ and $P=0.062$ ) was found for the SJ tests. We repeated the analyses separately in men and women and the results did not materially change (data not shown). Likewise, the mean estimates of the study phenotypes were similar in the $A C E \mathrm{II}+\mathrm{ID}$ and $A C T N 3 \mathrm{XX}$ and $A C E \mathrm{DD}$ and $A C T N 3$ $\mathrm{RR}+\mathrm{RX}$ groups (Table 2). We performed separate analyses comparing the $A C E \mathrm{DD}$ and $A C T N 3 \mathrm{RR}+\mathrm{RX}$ group versus the rest of subjects and the results remained the same (daca not shown). The observed power ranged between 0.78 and 0.85 .

We found no association between the $A C E$ DD and ACTN3 RR + RX genotype combination and performance ( $\geq 90 \mathrm{th}$ of the sex-specific percentile) (Fig. 2). The results remained the same after changing the cut-off point to $\geq 75$ th percencile or to $\geq 95$ th percentile, or after repeating the analysis by sex (data not shown).

\section{Discussion}

Our data suggest that the $A C E$ l/D polymorphism. individually or in combination with the $A C T N 3$ R577X polymorphism, does not have a major influence on explosive muscle power in young, non-arhletic adults, at least with the multi-joint exercise tests we used (see below). We only found a 'minor trend' for an influence of the $A C E \mathrm{l} / \mathrm{D}$ polymorphism on squat jump ress ( $P$ values of 0.063 and 0.062 for the dominant model in flight time and vertical 
Tuble 1 Mean estimates of study phenotypes by genotypes of $A C E$ I/D (rs1799752) polymorphism

\begin{tabular}{|c|c|c|c|c|c|c|c|c|c|}
\hline & \multicolumn{2}{|c|}{ II $(n=39)$} & \multicolumn{2}{|c|}{ ID $(n=129)$} & \multicolumn{2}{|c|}{$\mathrm{DD}(n=113)$} & \multirow[t]{2}{*}{$P$ add } & \multirow[t]{2}{*}{$P$ recess } & \multirow[t]{2}{*}{$P$ doir } \\
\hline & Mean & SEM & Mean & SEM & Mean & SEM & & & \\
\hline \multicolumn{10}{|l|}{ Vertical jump tests } \\
\hline \multicolumn{10}{|l|}{ SJ } \\
\hline Flight time (s) & 556.1 & 6.3 & 541.1 & 3.5 & 545.9 & 3.8 & 0.432 & 0.819 & 0.063 \\
\hline Verical displacement of $C G(\mathrm{~cm})$ & 38.2 & 0.9 & 36.2 & 0.5 & 36.9 & 0.5 & 0.451 & 0.773 & 0.062 \\
\hline \multicolumn{10}{|l|}{ CMJ } \\
\hline Flight time (s) & 564.6 & 6.6 & 552.8 & 3.7 & 556.5 & 4.0 & 0.546 & 0.863 & 0.155 \\
\hline Vertical displacement of CG (cm) & 39.4 & 0.9 & 37.7 & 0.5 & 38.3 & 0.5 & 0.609 & 0.771 & 0.160 \\
\hline \multicolumn{10}{|l|}{ Sprint tests } \\
\hline \multicolumn{10}{|l|}{30 in running start } \\
\hline Time at $15 \mathrm{~m}$ (s) (A) & 1.99 & 0.02 & 2.00 & 0.01 & 1.99 & 0.01 & 0.801 & 0.566 & 0.765 \\
\hline Time at $30 \mathrm{~m}(\mathrm{~s})$ (B) & 3.89 & 0.04 & 3.91 & 0.02 & 3.91 & 0.02 & 0.727 & 0.972 & 0.525 \\
\hline \multicolumn{10}{|l|}{30 in standing start } \\
\hline Time at $15 \mathrm{~m}(\mathrm{~s})(\mathrm{C})$ & 2.58 & 0.02 & 2.61 & 0.01 & 2.61 & 0.01 & 0.439 & 0.821 & 0.229 \\
\hline Time at $30 \mathrm{~m}$ (s) (D) & 4.53 & 0.04 & 4.56 & 0.02 & 4.56 & 0.02 & 0.686 & 0.924 & 0.510 \\
\hline \multicolumn{10}{|l|}{ Acceleration index } \\
\hline$C-A(s)$ & 0.59 & 0.02 & 0.61 & 0.01 & 0.62 & 0.01 & 0.332 & 0.455 & 0.385 \\
\hline$D-B(s)$ & 0.65 & 0.03 & 0.65 & 0.02 & 0.65 & 0.02 & 0.944 & 0.941 & 0.972 \\
\hline
\end{tabular}

Analyses adjusted for sex, age, weight and height. $P$ values before applying conrection for multiple testing

recess recessive (DD + ID vs. II), dom dominant (II + ID vs. DD), $S J$ squat juinp. $C M J$ counter-movement jump, $C G$ centre of gravity, $S E M$ standard enror of the mean

Table 2 Estimates of study phenotypes in the $A C E$ II + ID and $A C T N 3 \mathrm{XX}$ and $A C E \mathrm{DD}$ and ACTN3 RR + RX groups

SJ squat jump, CMJ countermovement jump, $C G$ centre of gravity. SEM standard error of the mean

* Analyses adjusted for sex, age, weight and height; $P$ values before applying correction for multiple testing

\begin{tabular}{|c|c|c|c|c|c|}
\hline & \multicolumn{2}{|c|}{$\begin{array}{l}A C E \mathrm{II}+\mathrm{ID} \text { and } A C T N 3 \\
\mathrm{XX}(n=36)\end{array}$} & \multicolumn{2}{|c|}{$\begin{array}{l}A C E \mathrm{DD} \text { and } A C T N 3 \\
\mathrm{RR}+\mathrm{RX}(n=97)\end{array}$} & \multirow[t]{2}{*}{$P *$} \\
\hline & Mean & SEM & Mean & SEM & \\
\hline \multicolumn{6}{|l|}{ Verical jump tests } \\
\hline \multicolumn{6}{|l|}{$\mathrm{SJ}$} \\
\hline Flight time (s) & 538.3 & 7.1 & 548.3 & 4.4 & 0.383 \\
\hline Vertical displacement of CG $(\mathrm{cm})$ & 35.8 & 1.0 & 37.2 & 0.6 & 0.373 \\
\hline \multicolumn{6}{|l|}{ CMJ } \\
\hline Flight tìne (s) & 549.6 & 7.3 & 558.2 & 4.5 & 0.641 \\
\hline Vertical displacement of $\mathrm{CG}(\mathrm{cm})$ & 37.3 & 1.0 & 38.5 & 0.6 & 0.636 \\
\hline \multicolumn{6}{|l|}{ Sprint tests } \\
\hline \multicolumn{6}{|l|}{$30 \mathrm{~m}$ running start } \\
\hline Time at $15 \mathrm{~m}(\mathrm{~s})(\mathrm{A})$ & 2.0 & 0.0 & 2.0 & 0.0 & 0.612 \\
\hline Time at $30 \mathrm{~m}$ (s) (B) & 4.0 & 0.0 & 3.9 & 0.0 & 0.420 \\
\hline \multicolumn{6}{|l|}{$30 \mathrm{~m}$ standing start } \\
\hline Time at $15 \mathrm{~m}(\mathrm{~s})(\mathrm{C})$ & 2.6 & 0.0 & 2.6 & 0.0 & 0.152 \\
\hline Time at $30 \mathrm{~m}$ (s) (D) & 4.6 & 0.0 & 4.6 & 0.0 & $0.10 \%$ \\
\hline \multicolumn{6}{|l|}{ Acceleration index } \\
\hline$C-A(s)$ & 0.6 & 0.0 & 0.6 & 0.0 & 0.340 \\
\hline$D-B(s)$ & 0.7 & 0.0 & 0.7 & 0.0 & 0.626 \\
\hline
\end{tabular}




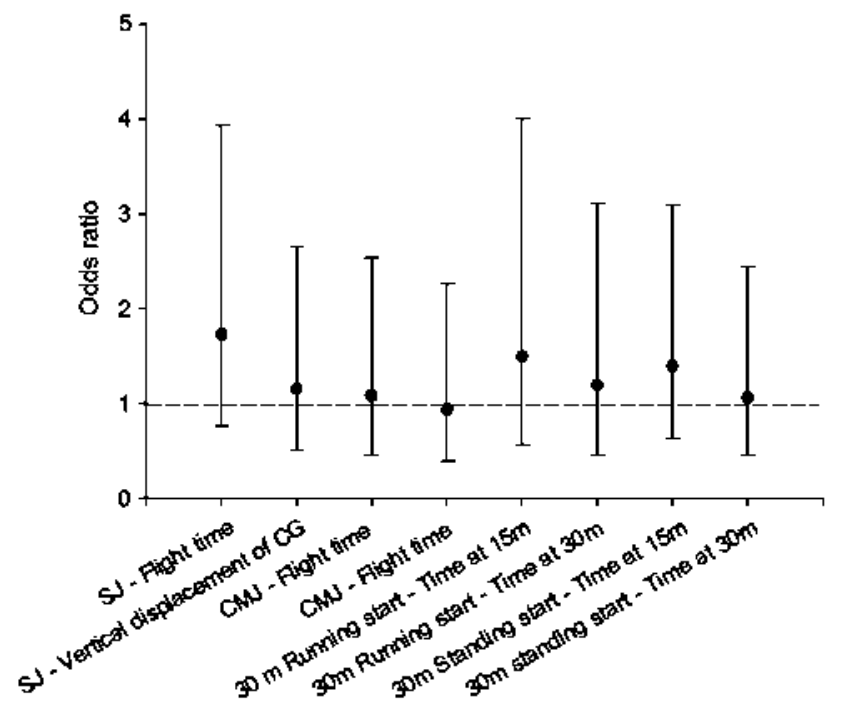

Fig. 2 Association between the ACE DD and ACTN3 RR + RX genotype combination and performance ( $\geq 90$ th of the sex-specific percentile). Values are odds ratio and $95 \%$ confidence intervals

displacement of centre of gravity, respectively). Thus, with the present design for phenotype assessment, the hypothesis that $A C E$ I/D and ACTN3 R557X genotypes might exert a combined influence on leg muscle phenotypes was not corroborated.

Though controversy exists (McCauley et al. 2009, 2010; Moran et al. 2006), the $A C E \mathrm{D}$ allele has been associated with power-related phenotypes in non-athletic populations (Giaccaglia et al. 2008; Hopkinson et al, 2004; Yamin et al, 2007); this allele has also been associated with elite "sprint" athletic performance (Myerson et al. 1999; Woods et al. 2001), though more recent data do not corroborate such association (Amir et al. 2007; Scotl et al. 2005, 2010). However, the association between leg 'explosive' muscle power and the $A C E$ I/D polymorphism had not been studied to date.

We assessed 'explosive' muscle power using jumping and sprinting testing tests in young, non-athletic adults. Jumping and sprinting are naturally occurring multi-joint movements in humans that involve the coordinated participation of the majority of lower limb muscles (Ashley and Weiss 1994; Brown and Weir 2001). On one hand, we believe that the tests we used for muscle phenotype assessment represent both a novelty and a strength of our study versus previous reports in the field that used other tests for muscle power assessment, e.g. isokinetic tests involving single-joint movements (e.g. knee-extension) at relatively low angular velocities $\left(\leq 240^{\circ} \mathrm{s}^{-1}\right.$ ) (McCauley et al. 2009, 2010). Indeed, during actual, natural high muscle power actions (e.g. sprint and jumps), angular velocities at the hip or knee joints can approach $800^{\circ}$ $1,000^{\circ} \mathrm{s}^{-1}$ (Bosco et al. 1983). The fact that we only used multi-joint tests can also be viewed as a limitation of our study because other factors aside from the skeletal muscle lissue per se (see below) could have influenced the results of our tests and masked any potential genotype effect. This is particularly true for sprinting. In this type of exercise task, owing to the short duration of the foot contact on the ground, the rate of force development (RFD) is the critical performance determinant. The RFD is, in turn, influenced by several factors such as muscle fibre type, synchronization of motor units, tendon stiffness, or lean mass of lower extremities (Perez-Gomez et al. 2008). In contrast, the ability of leg muscles (quadriceps) to produce power during the concentric phase of muscle contraction is the critical factor affecting stationary vertical jumps as the ones we used here (Ham et al, 2007). Future research in the field is necessary combining both single and multi-joint exercise tasks.

Scarce data are available on the combined influence of $A C E \mathrm{I} / \mathrm{D}$ and $A C T N 3 \mathrm{R} 577 \mathrm{X}$ polymorphisms on muscle power phenotypes. In elite athletes, data are rather controversial. We showed no significant combined influence of $A C T N 3 \mathrm{R} 577 \mathrm{X}$ and $A C E$ I/D variations on the peak muscle power output generated by elite endurance athletes during cycle-ergometer testing until exhaustion (Gomez-Gallego et al. 2009). No differences were found in peak power output between those cyclists with the ACE DD and ACTN3 $\mathrm{RR}+\mathrm{RX}$ and $A C E \mathrm{I}+\mathrm{ID}$ and $A C T N 3 \mathrm{XX}$ genotype combinations. More recently, Eynon et al. (2009) reported an association between the combination of both $A C E$ and ACTN3 polymorphisms and elite sprint athletic status (Eynon et al. 2009), yet they found that the most 'favourable' allele combination for a sprinter was the $A C T N 3 \mathrm{R}$ allele (i.e., theoretically power oriented) + the $A C E$ I allele [i.e. theoretically more endurance oriented according to other studies (Jones et al. 2002; Williams et al. 2000)]. With regard to this, in our study, we found no significant association between the $A C T N 3 \mathrm{R}$ allele $+A C E$ I allele combination (data not shown). As for non-athletic populations, our findings concur with recent data on elderly people showing no association (individually or combined) between power muscle phenotypes and ACE I/D + ACTN3 R577X genotype combinations (Bustamante-Ara et al. 2010).

Besides the aforementioned lack of data on single-joint tests for muscle power assessment, our study has other potential limitations. We did not measure the activity of the $A C E$ gene product (i.e. ACE) or circulating levels of the muscle growth factor angiotensin II. With regard to this, although serum $\mathrm{ACE}$ activity was suggested to be significantly dependent on $A C E$ genotypes in young Caucasian adults (with the highest enzymatic levels been found in the DD genotype), it does not seem to influence their muscle functional or contractile properties (McCauley et al, 2009). Further research is also necessary to assess the combined 
influence of other candidate genes with a potential effect on muscle phenotypes, e.g. the myoscatin gene.

In summary, though the $A C E \mathrm{I} / \mathrm{D}$ polymorphism is a strong candidate to modulate some exercise-related phenotypes or achletic perfonmance status, this polymorphism. alone or in combination with the $A C T N 3 \mathrm{R} 577 \mathrm{X}$ variation. does not seem to exert a major influence in the muscle 'explosive' power of non-athletic young healthy adults.

Acknowledgments This study was funded by the Consejo Superior de Deportes (CSD, ref \# UPR 10/08), Fondo de Investigaciones Sanicarias (FIS, ref. \# PS09/00194), and Swedish Council for Working Life and Social Research (FAS).

\section{References}

Alcaraz PE, Palao JM, Elvira Л (2009) Determining the optimal load for resisted sprint training with sled towing. J Strength Cond Res $23: 480-485$

Amir O. Amir R, Yamin C, Attias E, Eynon N, Sagiv M, Sagiv M, Meckel Y (2007) The ACE deletion allele is associated with Israeli elite endurance athletes. Exp Physiol 92:881-886

Ashley CD, Weiss LW (1994) Vertical jump performance and selected physiological characteristics of women. J Strength Cond Res 8:5-11

Bosco C. Mognoni P, Luhtanen P (1983) Relationship between isokinetic performance and ballistic movement. Eur J Appl Physiol Occup Physiol 51:357-364

Brown LE, Weir JP (2001) ASEP procedures recommendation I: accurate assessment of muscular strength. J Exp Physiol Online $4: 1-21$

Bustamante-Ara N, Santiago C, Verde Z, Yver T, Gomez-Gallego F, Rodriguez-Romo G, Gonzalez-Gil P. Serra-Rexach JA, Ruiz JR, Lucia A (2010) ACE and ACTN3 genes and muscle phenotypes in nonagenarians. Int $\mathbf{J}$ Sports Med 31:221-224

Chanock SJ, Manolio T, Boehnke M, Boerwinkle E, Hunter DJ, Thomas G, Hirschhom JN, Abecasis G. Altshuler D. BaileyWilson JE, Brooks LD, Cardon LR, Daly M, Donnelly P, Fraumeni JF Jr, Freimer NB, Gerhard DS, Gunter C, Guttmacher AE, Guyer MS, Harris EL, Hoh J, Hoover R, Kong CA, Merikangas KR, Morton CC, Palmer LJ, Phimister EG, Rice JP, Roberts J, Rotimi C. Tucker MA, Vogan KJ. Wacholder S, Wijsman EM, Winn DM, Collins FS (2007) Replicating genotype-phenotype associations. Nature 447:655-660

Delınonico MJ, Kostek MC, Doldo NA, Hand BD, Walsh S, Conway JM, Carignan CR. Roth SM. Hurley BF (2007) Alpha-actioin-3 (ACTN3) R577X polymorphism influences knee extensor peak power response to scrength training in older men and women. J Gerontol A Biol Sci Med Sci 62:206-212

Eyoon N, Alves AJ, Yamin C. Sagiv M, Duarte JA, Oliveira J, Ayalon M, Goldhammer E, Sagiv M, Meckel Y $(2009)$ Is there an ACE ID - ACTN3 R577X polymorphisms interaction that influences sprint performance? Int J Sports Med 30:888-891

Giaccaglia V, Nicklas B, Kritchevshy S, Mychalecky J, Messier S, Bleecker E, Pahor M (2008) Interaction between angiotensin converting enzyme insertion/deletion genotype and exercise training on knee extensor strength in older individuals. Int $\mathbf{J}$ Sports Med 29:40-44

Gomez-Gallego F、 Santiago C, Gonzalez-Freire M. Muniesa CA, Femandez Del Valle M. Perez M, Foster C, Lucia A (2009) Endurance performance: genes or gene combinations? Int $J$ Sports Med 30:66-72
Gordon SE, Davis BS, Carlson CJ, Booth FW (2001) ANG II is required for optimal overload-induced skeletal muscle hypertrophy. Am J Physiol Endocrinol Metab 280:E150-E159

Ham DJ, Knez WL, Young WB (2007) A deterministic model of the vertical jump: implications for training. J Strength Cond Res 21:967-972

Holın S (1979) A simple sequentially rejective multiple test procedure. Scand $\mathbf{J}$ Stat 6:65-70

Hopkinson NS, Nickol AH, Payne J, Hawe E, Man WD, Moxham J, Montgomery H. Polkey MI (2004) Angiotensin converting enzyme genotype and strength in chronic obstructive pulınonary disease. Am J Respir Crit Care Med 170:395-399

Jones A, Montgomery HE, Woods DR (2002) Human performance: a role for the ACE genotype? Exerc Sport Sci Rev 30:184-190

Lindpaintner K. Pfeffer MA, Kreutz R. Stampfer MJ, Grodstein F, LaMotte F, Buring J, Hennekens CH (1995) A prospective evaluation of an angiotensin-converting-enzyme gene polymorphism and the risk of ischemic heart disease. $\mathbf{N}$ Engl $\mathbf{J}$ Med 332:706-711

McCauley T, Mastana SS, Hossack J, Macdonald M, Folland JP (2009) Human angiotensin-converting enzyme I/D and alphaactinin 3 R577X genotypes and muscle functional and concractile properties. Exp Physiol 94:81-89

McCauley T, Mastana SS. Folland JP (2010) ACE I/D and ACTN3 $\mathrm{R} / \mathrm{X}$ polymorphisms and muscle function and muscularity of older Caucasian men. Eur J Appl Physiol 109:269-277

Moran CN, Vassilopoulos C, Tsiokanos A, Janurtas AZ, Bailey ME, Montgonery HE, Wilson RH. Pitsiladis YP (2006) The associations of ACE polymorphisms with physical, physiological and skill parameters in adolescents. Eur J Hum Genet 14:332-339

Myerson S, Hemingway H, Budget R. Martin J. Humphries S. Montgolnery H (1999) Human angiotensin I-converting enzyme gene and endurance performance. J Appl Physiol 87:1313-1316

North $\mathrm{KN}$, Yang N, Wattanasirichaigoon D, Mills M, Easteal S, Beggs AH (1999) A common nonsense mutation results in alphaactinin-3 deficiency in the general population. Nat Genet $21: 353-354$

Perez-Gomez J, Rodriguez GV, Ara I, Olmedillas H, Chavanen J, Gonzalez-Henriquez JJ. Dorado C, Calbet JA (2008) Role of muscle mass on sprint performance: gender differences? Eur J Appl Physiol 102:685-694

San Juan AF, Gomez-Gallego F, Canete S, Santiago C, Perez M, Lucia A (2006) Does complete deficiency of muscle alpha actinin 3 alter functional capacity in elderly women? A preliminary report. Br J Sports Med 40:el

Santiago C, Rodriguez-Romo G, Gomez-Gallego F, Gonzalez-Freire M, Y vert T, Verde Z, Naclerio F, Altmae S, Esteve-Lanao J, Ruiz JR, Lucia A (2009) Is there an association between ACTN3 R577X polymorphism and muscle power phenotypes in young. non-athletic adults? Scand J Med Sci Sports [Epub ahead of print]

Scott RA, Moran C, Wilson RH, Onywera V. Boit MK, Goodwin WH. Gohlke P. Payne J, Montgonnery H, Pitsiladis YP (2005) No association between angiotensin converting enzyme (ACE) gene variation and endurance athlete status in Kenyans. Comp Biochem Physiol A Mol Integr Physiol 141:169-175

Scott RA. Irving R, Irwin L, Morrison E, Charlton V. Austin K, Tladi D, Deason M, Headley SA, Kolkhorst FW, Yang N, North K, Pitsiladis YP (2010) ACTN3 and ACE genotypes in elite Jamaican and US sprinters. Med Sci Sports Exerc 42:107-112

Shaffer JP (1995) Multiple hypothesis testing. Ann Rev Psychol 46:561-584

Tejedor D, Castillo S, Mozas P, Jimenez E, Lopez M, Tejedor MT, Artieda M, Alonso R, Mata P. Simon L, Martinez A, Pocovi M (2005) Reliable low-density DNA array based on allele-specific probes for detection of 118 mutations causing familial hypercholesterolemia. Clin Chem 51:1137-1144 
Vincent B, De Bock $\mathbf{K}$, Ramaekers $M$, Van den Eede E, Van Leemputte M, Hespel P. Thomis MA (2007) ACTN3 (R577X) genotype is associated with fiber type distribution. Physiol Genomics 32:58-63

Wagner H, Thaller S, Dahse R, Sust M (2006) Biomechanical muscle properties and angiotensin-converting enzyme gene polymorphisin: a model-based study. Eur J Appl Physiol 98:507-515

Walsh S, Liu D, Metter EJ. Ferrucci L, Roth SM (2008) ACTN3 genotype is associated with muscle phenotypes in women across the adult age span. J Appl Physiol 105:1486-1491

Williams AG, Rayson MP. Jubb M, World M. Woods DR. Hayward M. Martio J, Humphries SE, Montgomery HE (2000) The ACE gene and muscle performance. Nature 403:614
Woods D, Hickman M, Jamshidi Y, Brull D, Vassiliou V, Jones A, Humphries S, Montgomery $\mathrm{H}$ (2001) Elite swimmers and the D allele of the ACE I/D polymorphism. Hum Genet 108:230-232

Yamin C, Amir O, Sagiv M, Attias E, Meckel Y, Eynon N, Sagiv M, Amir RE (2007) ACE ID genotype affects blood creatine kinase response to eccentric exercise. J Appl Physiol 103:2057-2061

Yang N, MacArthur DG, Gulbin JP, Hahn AG, Beggs AH, Easteal S, North K (2003) ACTN3 genotype is associated with human elite athletic performance. Am J Hum Genet 73:627-631

Young WB, MacDonald C. Flowers MA (2001) Validity of doubleand single-leg vertical jumps as tests of leg extensor muscle function. J Strength Cond Res 15:6-11 